\title{
Fenomenologia no campo da saúde da mulher: revisão de escopo
}

\author{
Phenomenology in the field of women's health: scope review \\ Fenomenología en el ámbito de la salud de la mujer: revisión del alcance
}

\section{Resumo}

A fenomenologia como corrente de pensamento e abordagem interpretativa, ancorada no paradigma emergente, tornou-se uma possibilidade de estudo e de análise da produção do cuidado humano. Esta revisão buscou mapear e examinar as produções científicas na abordagem fenomenológica desenvolvidas pela enfermagem na área temática da saúde da mulher. Seis bancos de dados foram pesquisados com o seguinte critério: mulheres adultas que receberam cuidado de saúde em quaisquer cenários. As buscas resultaram em 2.813 estudos, dos quais foram incluídos 113 estudos, sendo identificados quatro teóricos de suporte analítico, nove temas e 24 subtemas. As descobertas demonstram a crescente e potencial contribuição dessa abordagem teórico-metodológica na produção do conhecimento no campo da saúde da mulher. Também expressam como o cotidiano assistencial de enfermeiros, sustentados na fenomenologia, reconhece no diálogo com essas mulheres, o mundo da vida do cuidado em saúde. E essas descobertas apontam para novas práticas em saúde informadas/transformadas pela situação existencial concreta do ser humano, como uma perspectiva epistemológica que constitui o paradigma emergente.

Palavras-chave: Assistência à saúde; Fenomenologia; Saúde da mulher; Enfermagem; Brasil; Revisão.

\begin{abstract}
Phenomenology as a current of thought and interpretative approach, anchored in the emerging paradigm, has become a possibility of study and analysis of human care production. This review sought to map and examine the scientific productions in the phenomenological approach developed by Nursing in the thematic area of women's health. Six databases were researched with the following criteria: adult women who received health care in any setting. The searches resulted in 2,813 studies, of which one hundred and thirteen studies were included. Four analytical support theorists, nine themes and 24 sub-themes were identified. The findings show the growing and potential contribution of this theoretical-methodological approach in the production of knowledge in the field of women's health. They also express how the daily care of nurses, supported by phenomenology, re-cognizes the life world of health care in the dialogue with the women. These findings indicate new practices in health informed/transformed by the concrete existential situation of the human being, as an epistemological perspective that constitutes the emerging paradigm.
\end{abstract} Keywords: Health care; Phenomenology; Women's health; Nursing; Brazil; Revision. 


\begin{abstract}
Resumen
La fenomenología como corriente de pensamiento y enfoque interpretativo, anclada en el paradigma emergente, se ha convertido en una posibilidad de estudio y análisis de la producción del cuidado humano. Esta revisión buscó mapear y examinar las producciones científicas en el enfoque fenomenológico desarrollado por Enfermería en el área temática de la salud de la mujer. Se investigaron seis bases de datos con los siguientes criterios: mujeres adultas que recibieron atención médica en cualquier entorno. Las búsquedas dieron como resultado 2.813 estudios, de los cuales se incluyeron ciento trece estudios. Se identificaron cuatro teóricos del apoyo analítico, nueve temas y 24 subtemas. Los hallazgos muestran la creciente y potencial contribución de este enfoque teórico-metodológico en la producción de conocimiento en el campo de la salud de la mujer. También expresan cómo el cuidado diario de las enfermeras, apoyado en la fenomenología, reconoce el mundo de la vida del cuidado de la salud en el diálogo con las mujeres. Estos hallazgos indican nuevas prácticas en salud informadas / transformadas por la situación existencial concreta del ser humano, como perspectiva epistemológica que constituye el paradigma emergente.
\end{abstract}

Palabras clave: Cuidado de la salud; Fenomenología; La salud de la mujer; Enfermería; Brasil; Revisión.

\title{
1. Introdução
}

Para este estudo, reconhecemos a importância da produção científica pautada em resultados de pesquisas ancorados no paradigma dominante da ciência (Santos, 2003), fundamentada no positivismo, pós-positivismo e produzindo uma visão funcionalista. Ela enfoca um sentido ôntico na atenção à saúde e sustenta a prática baseada em evidência e no fazer técnico das ações dos profissionais. Entretanto, reconhecemos que há outras perspectivas epistemológicas que constituem o paradigma emergente (Santos, 2003), em que a visão social na ciência possibilita a ascensão do sentido ontológico na atenção à saúde, como possibilidade para o cuidado humano e profissional.

Dentre as perspectivas teórico-metodológicas contemporâneas, tem-se como opção a fenomenologia, movimento filosófico criado por Edmund Husserl, como reação ao empirismo positivista e à explicação causal dos fatos, sendo considerada uma das principais filosofias do século XX. Essas filosofias influenciam e sustentam as Ciências Humanas, que discutem a insuficiência metodológica da aplicação das Ciências da Natureza ao conhecimento do homem em sua totalidade existencial. Desse modo, as doenças precisam ser consideradas quanto à sua natureza estrutural - que permite entendê-las como são em si mesmas, em qualquer lugar no mundo - e quanto à sua natureza de conteúdo - que expressa a situação existencial concreta do ser doente (Capalbo, 1994).

Assim, este estudo, através do conceito da fenomenologia como elemento chave, enfoca a atenção à saúde da mulher em conformidade com a Agenda 2030 (United Nations General Assembly, 2015) em consonância com políticas públicas brasileiras (Brasil, 2017). Destacamos a necessidade e a pertinência das ações estratégicas na resposta aos Objetivos do Desenvolvimento Sustentável (ODS) relacionados às dimensões da vida humana, entre elas a da saúde, em especial a da mulher (Roma, 2019).

No contexto da saúde da mulher, articula-se o cuidado de enfermagem, cuja tendência atual é voltar-se para pessoas conscientes e livres e não para usuários anônimos, tendo esse reflexo nas produções acadêmicas e científicas. Entendemos que o trabalho (Capalbo, 1994) de explicitação, de aclaramento e de aplicação da fenomenologia à enfermagem cabe aos próprios enfermeiros. De tal modo, cabe ao pesquisador escolher uma abordagem para o desenvolvimento do conhecimento e considerar cuidadosamente os fundamentos filosóficos da fenomenologia que lhe forneçam suporte analítico para contribuir com o que já é conhecido ou não se sabe sobre um fenômeno de interesse (Lopez \& Willis, 2004).

Encontramos que a enfermagem tem buscado investigar a apropriação da fenomenologia na produção de estudos desenvolvidos por enfermeiras (1979-1996) (Damasceno \& Lopes, 1997), bem como caracterizar a produção acadêmica correlacionando as áreas do cuidar de enfermagem à luz dos referenciais teóricos. Essa busca ocorreu em banco de teses da Coordenação de Aperfeiçoamento de Estudos de Nível Superior (1987 a 2007) (Almeida et al., 2009). Outro estudo, investigou os Catálogos do Centro de Estudos e Pesquisas em Enfermagem (CEPEn) da Associação Brasileira de Enfermagem (ABEn), publicados no período compreendido entre 2003 e 2013 (Esquivel et al., 2016). Esses estudos mostraram a produção de 
dissertações e teses de enfermeiras brasileiras e nos conduziram para o objetivo de mapear e examinar as produções científicas na abordagem fenomenológica desenvolvidas pela enfermagem na área temática da saúde da mulher.

\section{Metodologia}

\section{Delineamento do estudo}

O desenho e condução desta revisão de escopo foram guiados de acordo com as etapas estabelecidas pelo Joanna Briggs Institute/JBI (Peters et al., 2020). Para dar início, foi estabelecida a questão de revisão como um roteiro para as etapas subsequentes. A pergunta foi: Quais as situações de saúde/doença vivenciadas por mulheres que são objetos de estudos fenomenológicos desenvolvidos pela Enfermagem? Sendo a pergunta secundária: Quais referenciais teórico-filosóficos foram utilizados? Foi usado para relatar este trabalho o checklist de itens preferenciais de relatório para revisões sistemáticas e extensão de meta-análises para revisões de escopo (PRISMA-ScR) (Tricco et al., 2018).

\section{Critérios de elegibilidade}

Os critérios foram elencados conforme os elementos do acrônico PCC (população, conceito e contexto) que estruturaram a questão de revisão. Quanto ao elemento população, foram incluídos os estudos que tinham como tema a saúde da mulher, sendo as participantes mulheres adultas que receberam cuidados de saúde. Não foram incluídos artigos de pesquisa cujos objetos estavam relacionados aos significados de cuidados com o filho, ao de ser mãe e de ser mulher.

Quanto ao elemento conceito, foram incluídos estudos que expressaram a abordagem fenomenológica na descrição do objeto de pesquisa, na manifestação dos autores acerca do referencial teórico e/ou metodológico, ou em procedimentos, isto é, na operacionalização (pólo morfológico e pólo técnico) da investigação. Foram excluídos os estudos que não expressaram a sustentação teórica e/ou metodológica na seção método e/ou o discurso fenomenológico na seção resultados do artigo.

Quanto ao elemento contexto, foram incluídos os estudos desenvolvidos pela enfermagem realizados em serviços de saúde do Brasil: hospitais, maternidades, casas de parto, ambulatórios de pré-natal, ambulatórios especializados, serviços de atenção primária e no domicílio. Foram excluídos estudos desenvolvidos em outros países mesmo que por autores brasileiros.

Foram selecionados estudos qualitativos publicados nos idiomas inglês, português ou espanhol, sem recorte temporal. Estes foram mapeados e criticamente revisados para criar uma síntese dos resultados.

\section{Fontes de informação, critérios de pesquisa e processo de pesquisa}

A Tabela 1 exibe os termos mapeados que foram utilizados para desenvolver uma estratégia de pesquisa completa para a PUBMED, que foi adaptada para SCOPUS, CINAHL, Web of Science, LILACS/BVS e SciELO, acessados até maio de 2020. As estratégias de pesquisa foram planejadas com o apoio de uma bibliotecária com experiência em estudos de revisão. Uma pesquisa inicial foi realizada para mapeamento dos termos contidos em títulos e resumos dos artigos relevantes e os termos do índice usados para descrever os artigos. A lista de referência dos artigos incluídos foi examinada para inclusão de estudos adicionais que atendessem aos critérios de elegibilidade.

Tabela 1 - Termos de pesquisa - PUBMED. Santa Maria, RS, Brasil, 2021.

\begin{tabular}{|c|c|}
\hline $\begin{array}{l}\text { Termos para população de } \\
\text { mulheres }\end{array}$ & $\begin{array}{l}\text { ("women"[Title/Abstract] OR "woman"[Title/Abstract]) OR "women's } \\
\text { health"[Title/Abstract]) OR "health, women's"[Title/Abstract]) OR "womens } \\
\text { health"[Title/Abstract]) OR "woman's health"[Title/Abstract]) OR "women's } \\
\text { health"[MeSH Terms]) }\end{array}$ \\
\hline $\begin{array}{l}\text { Termos para conceito de } \\
\text { fenomenologia }\end{array}$ & $\begin{array}{l}\text { ((("phenomenology"[Title/Abstract] OR "phenomenological"[Title/Abstract]) OR } \\
\text { "hermeneutic"[Title/Abstract]) OR "hermeneutics"[MeSH Terms]) }\end{array}$ \\
\hline
\end{tabular}

Fonte: Autores. 
Os resultados finais da busca incluíram 2.813 documentos e todas as citações identificadas foram agrupadas e exportadas para Mendeley (Mendeley Ltd., Elsevier, Netherlands) e duplicatas removidas. Os títulos e resumos foram examinados por dois revisores independentes para avaliação com base nos critérios de elegibilidade para a revisão. Os estudos que atendiam a esses critérios foram considerados potencialmente relevantes, recuperados na íntegra e o texto completo foi avaliado detalhadamente pelos revisores. Os motivos de exclusão dos estudos em texto completo que não atenderam aos critérios foram registrados. Os resultados da pesquisa foram apresentados em um diagrama de fluxo (Tricco et al., 2018). As divergências entre os revisores foram resolvidas por meio de discussão ou com um terceiro revisor em todas as etapas.

\section{Seleção de fontes de evidências e processo de coleta de dados}

Todos os artigos recuperados pela estratégia de busca entraram no processo de triagem e elegibilidade. Foram avaliados pelos dois revisores de modo independente, sendo realizada a leitura de título, resumo e, quando apropriado, o texto na íntegra para proceder a extração dos dados a partir dos critérios previamente definidos. Foi utilizado formulário próprio, no qual os revisores extraíram informações: ano de publicação, o objetivo do estudo, a abordagem metodológica (qual teórico foi utilizado), características da população estudada, a etapa de campo (técnica de coleta de dados, local/cenário, encerramento) e a técnica de análise. Quando houve conflito entre os revisores, esse foi resolvido por meio de discussão e, por vezes, um terceiro revisor da equipe foi convocado para estabelecer o consenso.

\section{Síntese dos resultados}

Os estudos foram organizados primeiramente quanto a cada referencial teórico descrito no artigo primário, a saber: Martin Heiddeger, Alfred Shutz, Maurice Merleau-Ponty e Max Scheler; e, também, pelo período de publicação e distribuição geográfica. Depois, mantendo na primeira organização, os estudos foram categorizados quanto ao tema da área da saúde que foi o foco das investigações e seus respectivos subtemas. Uma síntese foi desenvolvida, acompanhando os resultados tabulados e/ou gráficos. Os resultados foram descritos segundo cada referencial teórico.

\section{Resultados}

A estratégia de busca (Tabela 1) identificou um total de 2.813 estudos. Após excluir 799 artigos duplicados, foram analisados 2014 estudos (título e resumo), sendo excluídos 1794 estudos que não atenderam aos critérios de inclusão estabelecidos. Assim, 220 artigos foram considerados elegíveis para leitura do texto na íntegra e aplicação dos critérios de elegibilidade, sendo incluídos 113 artigos. Na fase de elegibilidade, 5 artigos foram excluídos porque tinham como participantes homens com câncer de mama, profissionais e equipes de saúde e parceiros masculinos, não caracterizando amostra populacional de mulheres (Figura 1). 
Figura 1 - Fluxograma dos artigos selecionados e incluídos na revisão.

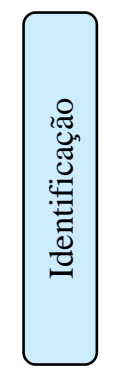

Registros identificados por meio de pesquisa em base de dados $(n=2813)$
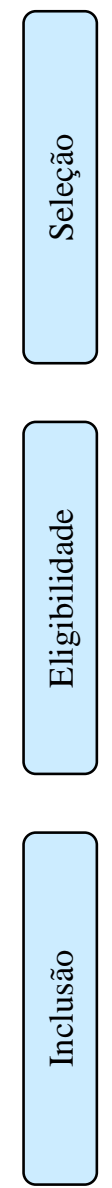
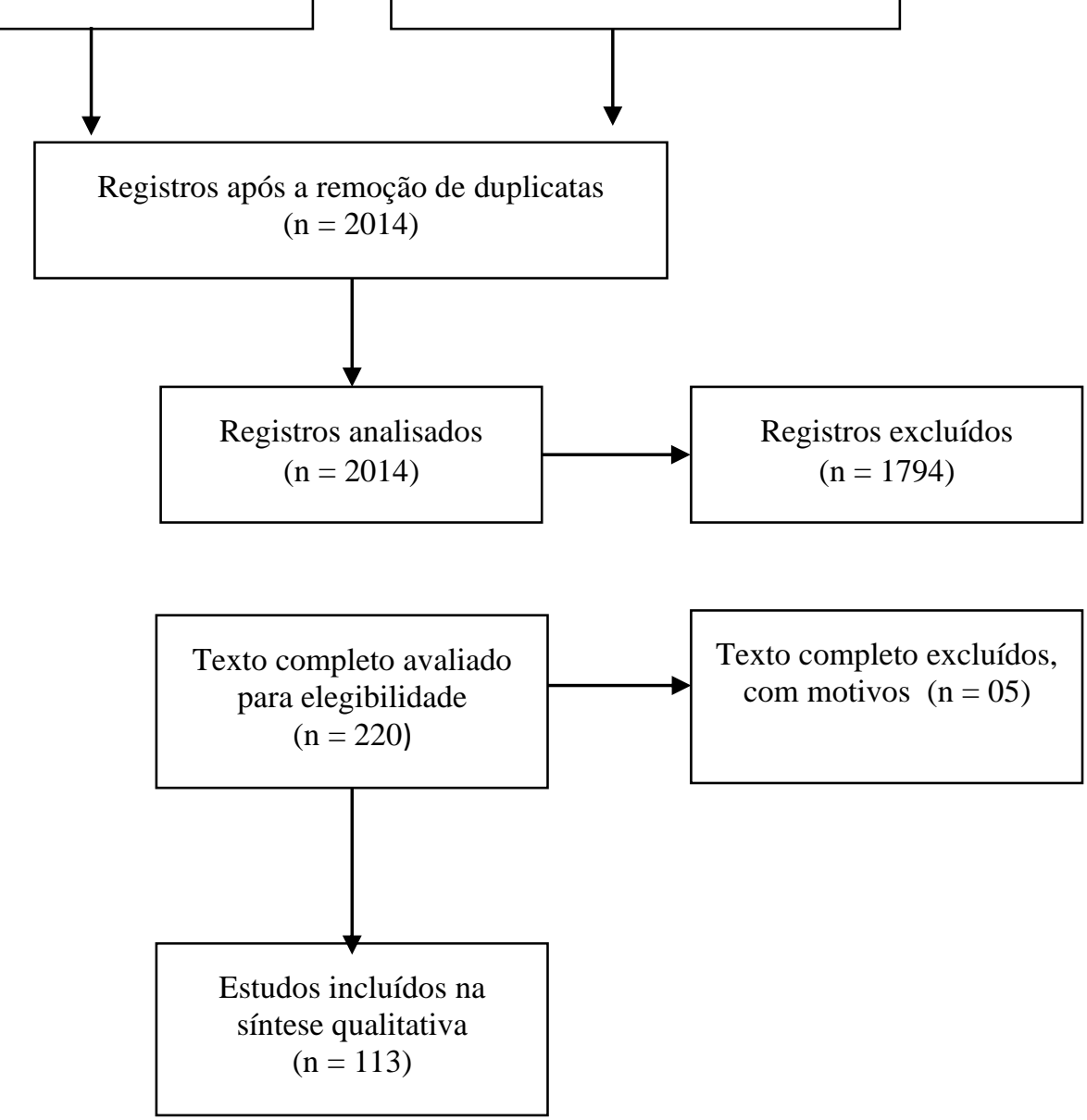

Fonte: Adequado a partir de Tricco et al. (2018).

As publicações ocorreram a partir de 1997, sendo que mais da metade foram publicadas no período de 2009 a 2020 (n =74). Os estudos incluídos totalizaram 113, agrupados segundo o referencial teórico adotado: Metade dos estudos $(54 \%, \mathrm{n}=$ 61) foram desenvolvidos utilizando o referencial teórico de Martin Heidegger (Heidegger, 2014), seguido de 27\% ( $\mathrm{n}=30$ ) que utilizaram o referencial teórico de Alfred Schütz (Schütz, 1972), 18 \% (n = 20) de Maurice Merleau-Ponty (Merleau-Ponty, 2011), $2 \%(\mathrm{n}=2)$ de Max Scheler (Scheler, 2012).

Apesar de desenvolver uma extensa estratégia de busca e pesquisa em várias bases de dados, a busca por essa análise do escopo não localizou estudos oriundos da região Norte do Brasil e apenas três foram encontrados na região Centro-Oeste. A região Sudeste concentra o maior número de produções (61), o que pode ser influenciado pelo maior número de programas de pós-graduação e o tempo de implantação dos mesmos. 
Tabela 2 - Distribuição geográfica das 113 publicações incluídas, por região e autores.

\begin{tabular}{lccccr}
\hline Filósofo/Região & \multirow{2}{*}{ Martin Heidegger } & \multirow{2}{*}{ Alfred Schütz } & $\begin{array}{c}\text { Maurice } \\
\text { Ponty }\end{array}$ & $\begin{array}{c}\text { Max } \\
\text { Scheler }\end{array}$ & Total/Região \\
\hline Sul & $16(26 \%)$ & $9(30 \%)$ & $8(40 \%)$ & - & $33(29 \%)$ \\
Sudeste & $31(51 \%)$ & $18(60 \%)$ & $8(40 \%)$ & - & $57(50 \%)$ \\
Centro-Oeste & $01(2 \%)$ & - & - & $02(100 \%)$ & $3(3 \%)$ \\
Nordeste & $13(21 \%)$ & $3(10 \%)$ & $4(20 \%)$ & - & $20(18 \%)$ \\
\hline Total/filósofo & $61(54 \%)$ & $30(26 \%)$ & $20(18 \%)$ & $02(2 \%)$ & $113(100 \%)$ \\
\hline
\end{tabular}

Fonte: Autores.

Os contextos em que os estudos foram realizados compreenderam ambulatório de serviços especializados (Oncologia, Infectologia, Obstetrícia, Ginecologia, serviços de atendimento de saúde mental e violências), unidades de internação hospitalares públicas ou privadas, Unidades Básicas de Saúde (UBS) ou Estratégias da Saúde da Família (ESF), casa de parto e domicílio. Destaca-se que quanto à caracterização das participantes dos estudos nem sempre foi possível identificar o quantitativo, nem a idade das participantes.

Quanto ao tema que foi o foco das investigações, 34 (30\%) foram da oncologia, 34 (30\%) foram relacionados ao tema da saúde sexual e saúde reprodutiva, 12 (11\%) de doenças infecciosas, 12 (11\%) de situações de violências, 8 (7\%) de demandas clínico-cirúrgicas, $6(5 \%)$ de situações de vulnerabilidades, 3 (3\%) de acometimentos do trabalho, 3 (3\%) de cuidados de si, e 1 (1\%) de saúde mental. Foi elaborada uma tabela (Tabela 2) para ilustrar os objetos de estudo das investigações alocando-os segundo às abordagens filosóficas dos estudos.

Tabela 3 - Distribuição dos temas e subtemas dos estudos incluídos por abordagem filosófica.

\begin{tabular}{|c|c|c|c|c|c|c|c|c|c|c|c|}
\hline \multirow[t]{2}{*}{ Tema } & \multirow[t]{2}{*}{ Subtema de artigos } & \multicolumn{2}{|c|}{ Martin Heidegger } & \multicolumn{2}{|c|}{$\begin{array}{l}\text { Alfred } \\
\text { Schütz } \\
\end{array}$} & \multicolumn{2}{|c|}{$\begin{array}{c}\text { Maurice } \\
\text { Merleau-Ponty }\end{array}$} & \multicolumn{2}{|c|}{$\begin{array}{c}\text { Max } \\
\text { Scheler }\end{array}$} & \multicolumn{2}{|c|}{ Total } \\
\hline & & $\mathrm{n}$ & $\%$ & $\mathrm{n}$ & $\%$ & $\mathrm{n}$ & $\%$ & $\mathrm{n}$ & $\%$ & & \\
\hline \multirow{3}{*}{ Oncologia } & Cérvico-uterina & 9 & 15 & 3 & 10 & 7 & 35 & - & & 19 & \\
\hline & Mama & 9 & 15 & - & - & - & - & - & & 9 & 34 \\
\hline & Cuidado oncológico & 6 & 10 & - & - & - & - & - & & 6 & \\
\hline \multirow{7}{*}{$\begin{array}{l}\text { Saúde sexual e } \\
\text { saúde reprodutiva }\end{array}$} & Processo parturitivo & 3 & 5 & 4 & 13 & 3 & 15 & - & & 10 & \\
\hline & Gestação & 5 & 8 & 3 & 10 & - & - & 2 & 100 & 10 & \\
\hline & Amamentação & 1 & 2 & 1 & 3 & - & - & - & & 2 & \\
\hline & Puerpério & - & - & 2 & 7 & 2 & 10 & - & & 4 & 34 \\
\hline & Consulta ginecológica & - & - & 2 & 7 & 1 & 5 & - & & 3 & \\
\hline & Aborto & - & - & 1 & 3 & - & - & - & & 1 & \\
\hline & Climatério & 2 & 3 & - & - & 2 & 10 & - & & 4 & \\
\hline \multirow{3}{*}{ Doenças Infecciosas } & HIV & 9 & 15 & - & - & - & - & - & & 9 & \\
\hline & HPV & 2 & 3 & - & - & - & - & - & & 2 & 12 \\
\hline & Leishmaniose & - & - & - & - & 1 & 5 & - & & 1 & \\
\hline \multirow{2}{*}{ Violências } & Doméstica & 2 & 3 & 4 & 13 & 3 & 15 & - & & 9 & \\
\hline & Sexual & - & - & 2 & 7 & 1 & 5 & - & & 3 & 12 \\
\hline \multirow{3}{*}{ Clínico-cirúrgico } & Cardiopatia & 2 & 3 & - & - & - & - & - & & 2 & \\
\hline & Cirurgia cardíaca & 4 & 7 & - & - & - & - & - & & 4 & 8 \\
\hline & Bariátrica & - & - & 2 & 7 & - & - & - & & 2 & \\
\hline \multirow{2}{*}{ Vulnerabilidades } & Envelhecimento & 1 & 2 & 3 & 10 & - & - & - & & 4 & \\
\hline & Situação de rua & - & - & 2 & 7 & - & - & - & & 2 & 6 \\
\hline Trabalho & Distúrbio osteomuscular & 3 & 5 & - & - & - & - & - & & 3 & 3 \\
\hline \multirow{2}{*}{ Cuidados de si } & No trabalho & 1 & 2 & - & - & - & - & - & & 1 & \\
\hline & No cotidiano & 2 & 3 & - & - & - & - & - & & 2 & 3 \\
\hline \multirow[t]{2}{*}{ Saúde mental } & Substâncias Psicoativas & - & - & 1 & 3 & - & - & - & & 1 & 1 \\
\hline & Total & 61 & 100 & 30 & 100 & 20 & 100 & 2 & 100 & \multicolumn{2}{|c|}{113} \\
\hline
\end{tabular}

Legenda: HIV - Vírus da Imunodeficiência Humana; HPV - Papilomavírus Humano. Fonte: Autores.

Os estudos que utilizaram como referencial teórico Martin Heidegger $(\mathrm{n}=61)$ foram publicados no período entre 1997 e 2020. Entre eles, os temas prevalentes nas investigações foram o da oncologia $(n=24)$, com as situações de: Câncer cérvico-uterino (9), Câncer de mama (9) e Cuidado oncológico (5). Seguido do tema da saúde sexual e saúde reprodutiva 
( $\mathrm{n}=11$ ) com as situações Parto (3), Gestação (5), Amamentação (1) e Climatério (2) e doenças infecciosas (n=11), sendo HIV (9) e HPV (2). Ainda, a coleta de dados se deu por meio de entrevista, totalizando, nos 61 estudos, 968 mulheres.

Os estudos que empregaram como referencial teórico Alfred Schütz foram publicados no período entre 2002 e 2020. O tema prevalente nas investigações foi o da saúde sexual e saúde reprodutiva (13), seguido do tema de situações de violências (6). Os 30 estudos ouviram por meio de entrevista 287 mulheres. Os estudos que utilizaram como referencial teórico Maurice Merleau-Ponty foram publicados no período entre 2000 e 2019. O tema mais prevalente nas investigações foi saúde sexual e saúde reprodutiva (8), seguido da Oncologia (7). Nos 20 estudos, foram ouvidas por meio de entrevista 180 mulheres. Os estudos que se basearam no referencial teórico Max Scheler foram publicados no período entre 2015 e 2018, sendo foco o tema da saúde sexual e saúde reprodutiva (2). Foram entrevistadas 62 mulheres.

\section{Discussão}

Esta revisão de escopo mapeou os teóricos de suporte analítico na abordagem fenomenológica utilizados nas investigações em que o objeto de estudo das produções científicas de enfermagem centrou-se na situação de saúde ou de doença vivenciada por mulheres.

Os estudos que se valeram de Martin Heidegger como referencial teórico e metodológico consideraram que o autor propõe um caminho metodológico em que descreve como o ser humano pode interrogar-se, procurando o sentido do ser como algo que se torna manifesto, percebido, compreendido e então conhecido para o ser humano. Martin Heidegger nasceu em 1889 na Alemanha e faleceu em 1976. Foi professor de Filosofia e Reitor na Universidade de Freiburg em Brisgaul (Alemanha). Sua principal obra foi o livro "Ser e Tempo", escrita no período pós-guerra (1927), em que o movimento filosófico do existencialismo na Europa era (re)visitado com intensa retomada dos questionamentos sobre a existência humana. Estudou os modos e maneiras de expressão do ser humano sendo um ser-no-mundo (Heidegger, 2014).

Foram identificadas sete áreas de interesse dos pesquisadores que trabalharam com esse referencial. No tema da oncologia, os estudos estavam relacionados às neoplasias de colo de útero, e os investigadores pretenderam compreender $o$ sentido da prevenção desse agravo durante o período gestacional (Moreira et al., 2013; Moreira \& Lopes, 2013; Moreira et al., 2017), e a vivência de mulheres com lesões precursoras do câncer do colo do útero (Melo et al., 2015). Os estudos também buscavam analisar o significado atribuído durante o pré-operatório (Ribeiro et al., 2019) e o pós-operatório de histerectomia (Salimena et al., 2009) e a braquiterapia (Rosa \& Sales, 2008). Após a histerectomia, o objeto de estudo foi o cotidiano da mulher (Salimena \& Souza, 2010) e o sentido da sexualidade (Salimena \& Souza, 2008).

As investigações pretendiam, ainda, compreender o significado (Paiva et al., 2015) e o impacto do diagnóstico do câncer de mama nas mulheres e seu modo de viver a partir da mastectomia (Almeida et al., 2015; Andrade et al., 2011), as vivências cotidianas após esse tipo de cirurgia ao buscar desvelar as expressões de sexualidade da mulher (Souto \& Souza, 2004), bem como o significado da vivência das mulheres desde o primeiro ciclo de quimioterapia e a cada novo ciclo (Camargo \& Souza, 2002; Conceição \& Lopes, 2008; Santos \& Gonçalves, 2006). Buscaram, também, desvelar sentidos da mulher na vivência do linfedema em decorrência do tratamento de câncer de mama e analisar propostas de cuidados na perspectiva do mundo da vida das mulheres (Paiva et al., 2020). Ainda com enfoque no cuidado, um estudo buscou compreender o significado do relaxamento com imaginação guiada para mulheres com câncer de mama (Toneti et al., 2019).

Quanto às questões relacionadas ao cuidado oncológico, os estudos buscaram desvelar os sentimentos experienciados no momento de receber o diagnóstico de câncer (Salci et al., 2009), as vivências com câncer ginecológico avançado (Silva \& Mereghi, 2006) e em ambiente familiar (Sales \& Molina, 2004). Bem como, estudaram as situações de câncer fora de possibilidade de cura, acerca da sua percepção quanto ao cuidado prestado pelos profissionais de saúde (Carvalho \& Mereghi, 2005; Carvalho \& Mereghi, 2008). Ainda, as mulheres pertencentes ao grupo de risco familiar discorreram acerca da 
prevenção secundária do câncer de mama (Melo \& Souza, 2012).

No tema da saúde sexual e saúde reprodutiva na gestação, o objetivo era desvelar o cotidiano das relações assistenciais da mulher que vivencia a gravidez de alto risco por doença cardíaca (Amorim et al., 2016). Ainda assim, a compreensão das experiências das mulheres com diabetes mellitus gestacional foi objeto de estudo (Araújo et al., 2013), tal como o significado de gestar diante de riscos reprodutivos em situação de cardiopatia (Amorim et al., 2018). A gestação de baixo risco foi investigada com vistas a compreender o significado de ser gestante em acompanhamento de pré-natal (Mesquita et al., 2015) e desvelar o ser gestante diante da possibilidade da amamentação (Souza, 1997).

No processo parturitivo, a publicação apresenta o significado desse processo (Amorim, et al., 2017) e a compreensão da parturiente em sua vivência e o sentido que funda seu comportamento (Simões \& Souza, 1997). As práticas obstétricas também foram investigadas para compreender o sentido dessas práticas na ótica das mulheres (Cavalcante et al., 2018). Quanto ao aleitamento materno, o objeto de estudo foi o significado expresso pelas mulheres acerca do apoio prestado em unidades básicas de saúde (Oliveira et al., 2010).

Nas questões da saúde sexual e saúde reprodutiva, o climatério foi investigado tendo em vista o conhecimento dos significados atribuídos por mulheres que vivenciam essa experiência (Almeida at al., 2007) e a compreensão dos significados que a mulher trabalhadora atribui à vivência do climatério e suas interfaces com a saúde mental (Soares et al., 2015).

No tema das doenças infecciosas, o HIV foi pesquisado na perspectiva de desvelar o movimento existencial na realização da profilaxia da transmissão vertical (Langendorf et al., 2016), o seu significado (Langendorf et al., 2015), bem como a experiência de cuidado (Langendorf et al., 2015; Langendorf et al., 2015). As questões de impossibilidade na relação de cuidado ao amamentar foram investigadas com o propósito de expor o sentido de ser mulher infectada pelo HIV (Padoin \& Souza, 2006), o sentido da cotidianidade (Padoin et al., 2010), o temor como modo de disposição dessa mulher (Padoin \& Souza, 2008), e a compreensão do mundo da vida (Padoin et al., 2011). Outro estudo publicado investigou o fato de se estar gestante e ter HIV (Machado et al., 2010). O subtema das infecções por papilomavírus humano foi pesquisado buscando apreender os sentimentos vivenciados por mulheres ao saberem do diagnóstico (Cestari et al., 2011) e compreenderem as necessidades de cuidado (Cestari et al. 2012).

No tema das situações de violências, os estudos buscaram compreender o significado da vivência conjugal com o agressor (Monteiro \& Souza, 2007), e o sentido da violência no cotidiano da prostituição (Moreira \& Monteiro, 2012). E, no tema das situações de vulnerabilidade, buscou-se compreender o significado de se estar envelhecendo na perspectiva das pessoas que vivenciam essa situação (Silva \& Boemer, 2009).

No tema clínico-cirúrgico, os pesquisadores buscaram descrever as emoções no cotidiano das mulheres submetidas a procedimentos de cirurgia cardíaca (Amorim et al., 2013), desvelar os sentidos de ser-aí-mulher após cirurgia cardíaca (Amorim et al., 2013) e seu cotidiano no dia a dia (Amorim et al., 2015). Também objetivaram analisar o movimento existencial da mulher com cardiopatia no contexto do planejamento reprodutivo (Amorim et al., 2020) evidenciando a historiografia e historicidade dessas mulheres (Amorim et al., 2015). Quando a mulher se encontrava hospitalizada por cardiopatia e desenvolveu lesão por pressão, o objetivo de pesquisa foi revelar os significados deste vivido (Silva et al., 2017).

No tema do trabalho, as investigações buscaram compreender ser mulher trabalhadora de enfermagem e portadora de Distúrbio Osteomuscular (DORT) (Baptista et al., 2011) e o seu cotidiano (Leite et al., 2007a; Leite et al., 2007b). Convergem com o tema cuidado de si em que o cenário foi no trabalho e no cotidiano assistencial da enfermagem (Elias et al., 2014). No cotidiano da mulher, o tema foi o sentido que funda o comportamento da mulher no cuidado com a própria saúde (Simões \& Souza, 1999). Quando a mulher era a cuidadora do companheiro com câncer, foi desvelado o significado do cuidado de si (Piolli et al., 2018).

Os estudos que utilizaram Alfred Schütz como referencial teórico e metodológico destacaram os conceitos de ação, 
relações sociais e compreensão. O filósofo austríaco Alfred Schütz (1899-1959) desenvolveu seus estudos após sua ida para os Estados Unidos e contribuiu para estabelecer os fundamentos de uma Fenomenologia Sociológica. Ele se apoiou na estrutura teórica do Hussel e nos conceitos de intencionalidade, intersubjetividade e mundo da vida (Schütz, 1972). Isso permite compreender os fenômenos sociais a partir do método de análise descritiva e o significado atribuído pelo sujeito à ação na constituição da experiência cotidiana (Jesus et al., 2013).

Foram identificados 30 estudos e seis áreas de interesse dos pesquisadores que trabalharam com o referencial de Schütz. Na área da oncologia, os autores buscaram apreender as expectativas das mulheres em braquiterapia ginecológica com relação à consulta de enfermagem (Araújo et al., 2018; Araújo et al., 2017), e também em relação à realização de procedimento cirúrgico como histerectomia (Merighi et al., 2012).

$\mathrm{Na}$ saúde sexual e saúde reprodutiva, quando o subtema foi o parto, buscaram a intencionalidade na procura dos serviços de assistência hospitalar (Giaxa \& Ferreira, 2011; Ferreira et al., 2017) e em casa de parto (Gonçalves et al., 2011), como também a vivência das mulheres em relação ao tipo de parto (Silva et al., 2014). Durante a gestação das mulheres, os pesquisadores investigaram as necessidades relacionadas ao cuidado que foram referidas por elas (Merighi et al., 2007; Sodré et al., 2010) e na perspectiva da portadora de esclerose múltipla (Belarmino et al., 2020). Esse objeto também esteve presente nas investigações durante o puerpério (Merighi et al., 2006; Merighi et al., 2007). Quanto ao subtema da amamentação, identificou-se estudo relacionado ao típico da ação das mulheres (Souza et al., 2009).

Em relação ao subtema da consulta ginecológica, os estudos buscaram identificar o conhecimento e a experiência na realização do exame colpocitológico (Jorge et al., 2011; Merighi et al., 2002). Além disso, o aborto foi investigado na perspectiva do cuidado experenciado pelas mulheres (Domingos et al., 2011).

Foram classificados os estudos em situações de vulnerabilidade considerando a situação de rua, de institucionalização e de envelhecimento. Buscou-se compreender a experiência das mulheres em situação de rua (Biscotto et al., 2016) e quando institucionalizadas durante a gestação (Reis et al., 2008). No tema envelhecimento, investigou-se as motivações das mulheres quando participavam de grupos antitabagismo (Caldeira et al., 2016), as expectativas quanto ao processo de envelhecimento (Merighi et al., 2013) e suas experiências em relação à violência doméstica nesta etapa da vida (Souto et al., 2015).

Os estudos que investigaram as violências se direcionaram para a violência sexual, buscando compreender as ações cotidianas após tal vivência (Trigueiro et al., 2017) e os motivos para não adesão ao seguimento do atendimento ambulatorial (Trigueiro et al., 2018). Já aqueles em que o foco foi violência doméstica, buscou-se compreender as perspectivas e as necessidades da mulher em relação ao cuidado de enfermagem, quais os seus motivos para realizar a denúncia e o típico da ação de denunciar (Vieira et al., 2011a; Vieira et al. 2011b; Vieira et al., 2012; Vieira et al., 2013).

Também foi investigado à luz de Alfred Schutz o processo de decisão da mulher obesa para realizar a cirurgia bariátrica e as experiências dessas mulheres no pós-operatório (Oliveira et al., 2014; Oliveira et al., 2016). Outro estudo também utilizou a fenomenologia social para compreender os motivos atribuídos por mulheres ao abuso de substâncias psicoativas (Soccol et al., 2018).

O terceiro referencial teórico identificado nos estudos foi o de Maurice Merleau-Ponty. Filósofo francês (1908-1961), que reconhece o corpo inserido no mundo como constituição da subjetividade e expressividade da fala. Para ele, a fenomenologia se caracteriza pelo reconhecimento de que o sensível adquire relevância na vida do ser humano, e que pensamento não se separa da vida e dos acontecimentos, uma vez que se encontra inserido no mundo. Desse modo, o corpo será recortado pela historicidade, sendo a realidade do corpo que nos permite sentir e perceber o mundo (Merleau-Ponty, 2011).

Identificamos 20 estudos em que o foco de investigação foi em quatro áreas: oncologia, saúde sexual e saúde reprodutiva, doenças infecciosas e situações de violências. Quanto à oncologia, os autores buscaram compreender a percepção 
do corpo da mulher desde a descoberta do câncer de mama (Corbellini, 2001), a eminência da mastectomia (Bittencourt \& Cadete, 2001), o tratamento desse tipo de câncer. (Corbellini \& Comiotto, 2000), os impactos da mastectomia no corpo (Madeira et al., 2007; Azevedo \& Lopes, 2006), o uso de prótese mamária (Azevedo \& Lopes, 2005) e a vivência da quimioterapia (Medeiros et al., 2019).

Em relação à saúde sexual e saúde reprodutiva, os autores buscavam compreender a corporeidade de gestantes de gerar um filho em situação de alto risco ou vivendo com HIV (Oliveira et al., 2011; Arcoverde et al., 2015; Coelho \& Motta, 2005). Quando o subtema foi puerpério, os autores direcionaram as questões para a amamentação e a corporeidade (Lima et al., 2006). Também direcionaram para a assistência à mulher no período do climatério e o exercício da sexualidade nesse período (Gonçalves \& Merighi, 2005; Gonçalves \& Merighi, 2009). E, ainda, para o subtema consulta ginecológica com o significado da realização do exame colpocitológico (Paula \& Madeira, 2003).

Para compreender a vivência das situações de violência doméstica, as questões se referiam à resiliência das mulheres e à coexistência com o agressor (Oliveira et al., 2015; Labronici, 2012; Ferraz \& Labronici, 2015). Também buscou desvelar o significado da violência sexual na manifestação da corporeidade (Labronici et al., 2010). Quanto ao tema relacionado às doenças infecciosas, o subtema Leishmaniose (Silva \& Lopes, 2004) buscou compreender a percepção do corpo pela mulher portadora da patologia.

O quarto referencial teórico filosófico identificado em dois estudos foi Max Scheler, outro filósofo alemão (18741928) conhecido por seu trabalho sobre fenomenologia, ética e antropologia filosófica, do mesmo jeito que por sua contribuição à filosofia dos valores (Scheler, 2012). Apresenta o conhecimento dos valores e a visão de um ser humano em três níveis de evolução: 1) dos valores sensoriais (prazer e dor); 2) valores afetivos vinculados às emoções que compõem a ordem da psyque; e 3) no nível espiritual, que preserva os valores do que é espiritual ou sagrado (o mais elevado).

Os autores dos estudos primários tinham suas lentes para a situação vivida pela mulher durante a gestação (tema saúde sexual e saúde reprodutiva) sendo o objeto de estudo os valores instituídos pelas mulheres acerca da qualidade do pré-natal (Silva et al., 2018). E, outro estudo buscou analisar os valores de gestantes acerca da acessibilidade aos exames durante o prénatal de risco habitual (Silva et al., 2015).

\section{Limitações e Conclusões}

Quanto à limitação deste estudo declaramos que a busca não recuperou alguns artigos relacionados à saúde da mulher, pois esses muitas vezes são indexados com descritores/palavras-chave relacionados à saúde da criança, devido às interfaces entre as áreas de conhecimento materno-infantil.

Identificamos o predomínio de três referenciais teóricos que foram Martin Heidegger, Alfred Schütz e Maurice Merleau-Ponty. Em relação à distribuição geográfica das produções, a região Sudeste se destaca com a maioria das produções e a Norte não apresentou produções nesta pesquisa. Quanto aos temas, o foco da maioria das investigações foi o tema saúde sexual e saúde reprodutiva e oncologia. A principal técnica de coleta de dados foi a entrevista individual, com algumas em grupo. Como uma expressão do mapeamento, o quantitativo de participantes nos estudos incluídos totalizou 1.497 mulheres.

As descobertas demonstraram que foi crescente a inserção dessa abordagem no desenvolvimento da produção do conhecimento nesse campo específico de investigação. E, quando analisada a relação do objeto de estudo com a abordagem teórico-metodológica, os percentuais acerca do tema foram distintos e guardavam convergência com o pensamento filosófico dos autores. O que indica que os autores articulam o tema da saúde das mulheres com a abordagem que orienta o estudo e identificam os pressupostos filosóficos.

O potencial da contribuição desse conhecimento no campo da saúde da mulher expressa que enfermeiras e enfermeiros reconhecem no diálogo com essas mulheres, o mundo da vida do cuidado em saúde, sustentados na abordagem 
fenomenológica como perspectiva epistemológica que constitui o paradigma emergente. Este estudo poderá influenciá-los ao uso da fenomenologia na produção de conhecimento para o cuidado humano no cotidiano assistencial e transformar as suas práticas em saúde informadas pela expressão da situação existencial concreta do ser humano.

\section{Financiamento}

Este artigo foi escrito como parte de um estudo de Estágio de Pós-Doutorado Sênior com financiamento do Conselho Nacional de Desenvolvimento Científico e Tecnológico (CNPq) do Brasil (Processo no 104238 / 2018-6).

\section{Referências}

Almeida, I. S., Crivaro, E. T., Salimena, A. M. O., \& Souza, I. E. O. (2009). O caminhar da enfermagem em fenomenologia: revisitando a produção acadêmica. Revista Eletrônica de Enfermagem, 11(3), 695-9. http://www.fen.ufg.br/revista/v11/n3/v11n3a30.htm

Almeida, L. H. R. B., Luz, M. H. B. A., \& Monteiro, C. F. S. (2007). Ser mulher no climatério: uma análise compreensiva pela enfermagem. Revista Enfermagem UERJ, 15(3), 370-5. http://www.facenf.uerj.br/v15n3/v15n3a08.pdf

Almeida, T. G., Comassetto, I., Alves, K. M. C., Santos, A. A. P., Silva, J. M. O., \& Trezza, M. C. S. F. (2015). Vivência da mulher jovem com câncer de mama e mastectomizada. Escola Anna Nery Revista de Enfermagem, 19(3), 432-8. 10.5935/1414-8145.20150057

Amorim, T. V., Salimena, A. M. O., \& Souza, I. E. O. (2015). Historicidad y historiografía: contribución de la entrevista fenomenológica para Enfermería. Cultura de los Cuidados, 19(41), 71-81. 10.14198/cuid.2015.41.09

Amorim, T. V., Salimena, A. M. O., Melo, M. C. S. C., \& Souza, I. E. O. (2013). Emoções manifestas pelo ser-mulher-no-mundo após cirurgia cardíaca. Cogitare Enfermagem, 18(2), 268-273. 10.5380/ce.v18i2.32576

Amorim, T. V., Salimena, A. M. O., Melo, M. C. S. C., Souza, I. E. O., \& Silva, L. F. (2013). Sentidos do ser-aí-mulher-após-cirurgia-cardíaca à luz de Heidegger. Revista da Rede de Enfermagem do Nordeste, 14(5), 988-95. http://periodicos.ufc.br/rene/article/view/3635/2877

Amorim, T. V., Salimena, A. M. O., Souza, I. E. O., Melo, M. C. S. C., Silva, L F., \& Cadete, M. M. M. (2015). Temporalidade da mulher após cirurgia cardíaca: contribuições para o cuidado de enfermagem. Revista Brasileira de Enfermagem, 68(6), 1056-62. 10.1590/0034-7167.2015680609i

Amorim, T. V., Souza, I. E. O., Salimena, A. M. O., Carvalho, A. L. O., Silvia, L. F., \& Langendorf, T. F. (2017). Promoção da saúde materna a partir do vivido do parto de mulheres cardiopatas. Cogitare Enfermagem, 22(4), e51641. 10.5380/ce.v22i4.51641

Amorim, T. V., Souza, I. E. O., Salimena, A. M. O., Melo, M. C. S. C., Paiva, A. C. P. C., \& Moura, M. A. V. (2016). Cotidiano da gravidez de risco por cardiopatia: estudo fenomenológico das relações assistenciais. Escola Anna Nery Revista de Enfermagem, 20(4), e20160091. 10.5935/1414-8145.20160091

Amorim, T. V., Souza, I. E. O., Salimena, A. M. O., Queiroz, A. B. A., \& Elias, E. A. (2020). Mulheres com cardiopatia no contexto do planejamento reprodutivo: contribuições da hermenêutica fenomenológica. Escola Anna Nery Revista de Enfermagem, 24(1), e20190164. 10.1590/2177-9465-EAN-20190164

Amorim, T. V., Souza, I. E. O., Salimena, A. M. O., Queiroz, A. B. A., Moura, M. A. V., \& Melo, M. C. S. C. (2018). Risco reprodutivo em gestantes portadoras de cardiopatia: o mundo vivido direcionando o cuidado em saúde. Texto \& Contexto - Enfermagem, 27(2), e3860016. 10.1590/0104070720180003860016

Andrade, G. N., Panza, A. R., \& Vargens, O. M. C. (2011). As redes de apoio no enfrentamento do câncer de mama: uma abordagem compreensiva. Ciência, Cuidado e Saúde, 10(1), 82-8. 10.4025/cienccuidsaude.v10i1.10609

Araújo, C. R. G., Rosas, A. M. M. T. F., Menezes, H. F., Cunha, M. A. L. C., Santiago, A. S., \& Rodrigues, B. M. R. D. (2018). O Significado da dor para mulheres em braquiterapia ginecológica: abordagem fenomenológica na consulta de enfermagem. Revista de Pesquisa: Cuidado é Fundamental Online, 10(3), 612-8. 10.9789/2175-5361.2018.vi.612-618

Araújo, C. R. G., Rosas, A. M. M. T. F., Menezes, H. F., Pinto, A. C. S., \& Rodrigues, B. M. R. D. (2017). O fenômeno vivido por mulheres na consulta de enfermagem na braquiterapia ginecológica. Texto \& Contexto - Enfermagem, 26(2), e00140016. 10.1590/0104-07072017000140016

Araújo, M. F. M., Pessoa, S. M. F., Damasceno, M. M. C., \& Zanetti, M. L. (2013). Diabetes gestacional na perspectiva de mulheres grávidas hospitalizadas. Revista Brasileira de Enfermagem, 66(2), 222-7. 10.1590/S0034-71672013000200011

Arcoverde, M. A. M., Conter, R. S., Silva, R. M. M., \& Santos, M. F. (2015). Sentimentos e expectativas da gestante vivendo com HIV: um estudo fenomenológico. Revista Mineira de Enfermagem, 19(3), 554-60. 10.5935/1415-2762.20150043

Azevedo, R. F., \& Lopes, R. L. M. (2005). Merleau-Ponty e a compreensão da vivência de mulheres mastectomizadas em uso de prótese. Revista Enfermagem UERJ, 13(2), 188-93.

Azevedo, R. F., \& Lopes, R. L. M. (2006). Vivência do diagnóstico de câncer de mama e de mastectomia radical: percepção do corpo feminino a partir da fenomenologia Online Brazilian Journal of Nursing (Online), 5(1), 48-54. http://www.objnursing.uff.br/index.php/nursing/article/view/137/38

Baptista, P. C. P., Merighi, M. A. B., \& Silva, A. (2011). Angústia de mulheres trabalhadoras de enfermagem que adoecem por distúrbios osteomusculares relacionados ao trabalho. Revista Brasileira de Enfermagem, 64(3), 438-44. 10.1590/S0034-71672011000300005 
Belarmino, A. C., Azevedo, L. J. M., Teixeira, A. K. M., Sousa, B. A. T., Alves, L. C., \& Ferreira Junior, A. R. (2020). Gestante com esclerose múltipla: reflexão fenomenológica da mulher quanto ao parto. Avances en Enfermería, 38(1), 77-86. 10.15446/av.enferm.v38n1.81405

Biscotto, P. R., Jesus, M. C. P., Silva, M. H., Oliveira, D. M., \& Merighi, M. A. B. (2016). Compreensão da vivência de mulheres em situação de rua. Revista da Escola de Enfermagem da USP, 50(5), 750-6. 10.1590/S0080-623420160000600006

Bittencourt, J. F. V., \& Cadete, M. M. M. (2001). Pré Operatório de mastectomia sob a ótica da mulher que o vivencia. Revista SOBECC, 6(4), 22-7.

Brasil. (2017). Ministério da Saúde. Política nacional de atenção integral à saúde da mulher - PNAISM. Documento de apoio às Conferências de Saúde das Mulheres Municipais, Regionais e Estaduais. Brasília, DF. http://conselho.saude.gov.br/ultimas_noticias/2017/doc/05maio02_2cnsmu_MS.pdf

Caldeira, S., Parecy, S. M., Maraschin, M. S., Ross, C., Machineski, G. G., \& Ribeiro, S. A. (2016). Vivência de mulher idosa tabagista: um estudo na Fenomenologia Social de Alfred Schütz. Revista Mineira de Enfermagem, 20, e953. 10.5935/1415-2762.20160022

Camargo, T. C., \& Souza, I. E. O. (2002). O ex-sistir feminino enfrentando a quimioterapia para o câncer de mama: um estudo de enfermagem na ótica de Martin Heidegger. Revista Enfermagem UERJ, 10(2), 104-8.

Capalbo, C. (1994). Abordando a enfermagem a partir da fenomenologia. Revista Enfermagem UERJ, 2(1), 70-6.

Carvalho, M. V. B., \& Merighi, M. A. B. (2005). O cuidar no processo de morrer na percepção de mulheres com câncer: uma atitude fenomenológica. Revista Latino-Americana de Enfermagem, 13(6), 951-9. 10.1590/S0104-11692005000600006

Carvalho, M. V. B., \& Merighi, M. A. B. (2008). O significado do cuidar no processo de morrer na voz das mulheres. Revista Bioética, 16(2), 259-72. https://revistabioetica.cfm.org.br/index.php/revista_bioetica/article/view/72/75

Cavalcante, R. J. G., Moreira, R. C. R., Peñarrieta, E. C. S., \& Barrêto, L. G. P. (2018). A fenomenologia como possibilidade de um olhar atentivo para as práticas obstétricas. Acta Paulista de Enfermagem, 31(1), 71-8. 10.1590/1982-0194201800011

Cestari, M. E. W., Merighi, M. A. B., \& Baptista, P. C. P. (2011). Sentimentos vivenciados por mulheres infectadas pelo HPV ao saberem do diagnóstico da doença. Ciência, Cuidado e Saúde, 10(3), 422-9. 10.4025/cienccuidsaude.v10i3.10054

Cestari, M. E. W., Merighi, M. A. B., Garanhani, M. L., Cardeli, A. A. M., Jesus, M. C. P., \& Lopes, D. F. M. (2012). Necessidades de cuidados de mulheres infectadas pelo papilomavírus humano: uma abordagem compreensiva. Revista da Escola de Enfermagem da USP, 46(5), 1082-7. 10.1590/S008062342012000500007

Coelho, D. F., \& Motta, M. G. C. (2005). A compreensão do mundo vivido pelas gestantes portadoras do vírus da imunodeficiência humana (HIV). Revista Gaúcha de Enfermagem, 26(1), 31-41. https://seer.ufrgs.br/RevistaGauchadeEnfermagem/article/view/4538/2468

Conceição, L. L., \& Lopes, R. L. M. (2008). O cotidiano de mulheres mastectomizadas: do diagnóstico à quimioterapia. Revista Enfermagem UERJ, 16(1), 2631.

Corbellini, V. L. (2001). Câncer de mama: encontro solitário com o temor do desconhecido. Revista Gaúcha de Enfermagem, 22(1), 42-68. https://www.scielo.br/scielo.php?script=sci_nlinks\&ref=000088\&pid=S0080-6234200700020002000003\&lng=en

Corbellini, V. L., \& Comiotto, M. S. (2000). Hoje eu me sinto em paz, eu deito agradecendo a Deus; se nós não temos fé, nós não somos ninguém. Revista $O$ Mundo da Saúde, 24(6), 510-4.

Damasceno, M. M. C.; \& Lopes, R. L. M. (1997). A apropriação da fenomenologia pela enfermagem: pesquisas fenomenológicas desenvolvidas por enfermeiras. Pós-Graduação/Departamento de Enfermagem/Universidade Federal do Ceará.

Domingos, S. R. F., Merighi, M. A. B., \& Jesus, M. C. P. (2011). Vivência e cuidado no abortamento espontâneo: um estudo qualitativo. Online Brazilian Journal of Nursing (Online), 10(2). 10.5935/1676-4285.20113236

Elias, E. A., Souza, I. E. O., \& Vieira, L. B. (2014). Significados do cuidado-de-si-mesmas de mulheres profissionais de enfermagem em uma unidade de pronto atendimento. Escola Anna Nery Revista de Enfermagem, 18(3), 415-20. 10.5935/1414-8145.20140059

Esquivel, D. N., Silva, G. T. R., Medeiros, M. O., Soares, N. R. B., Gomes, V. C. O., \& Costa, S. T. L. (2016). Produção de estudos em enfermagem sob o Referencial da fenomenologia. Revista Baiana de Enfermagem, 30(2), 1-10. 10.18471/rbe.v30i2.15004

Ferraz, M. I. R., \& Labronici, L. M. (2015). Fragmentos de corporeidades femininas vítimas de violência conjugal: uma aproximação fenomenológica. Texto \& Contexto - Enfermagem, 24(3), 842-9. 10.1590/0104-07072015003030014

Ferreira, M. L. S. M., Giaxa, T. E., Popim, R. C., \& Meneguin, S. (2017). Dor como motivo de busca para assistência ao trabalho de parto hospitalar. Revista Eletrônica de Enfermagem, 19, a12. 10.5216/ree.v19.41332

Giaxa, T. E. P., \& Ferreira, M. L. S. M. (2011). Miedo e inseguridad de la gestante durante el trabajo de parto como motivos para la demanda de internación precoz. Investigación y Educación en Enfermería, 29(3), 363-9. Disponible en: http://www.redalyc.org/articulo.oa?id=105222406004

Gonçalves, R., \& Merighi, M. A. B. (2005). O climatério: a corporeidade como berço das experiências do vivido. Revista Brasileira de Enfermagem, 58(6), 692-7. 10.1590/S0034-71672005000600012

Gonçalves, R., \& Merighi, M. A. B. (2009). Reflexões sobre a sexualidade durante a vivência do climatério. Revista Latino-Americana de Enfermagem, 17(2), 160-6. 10.1590/S0104-11692009000200004

Gonçalves, R., Aguiar, C. A., Merighi, M. A. B., \& Jesus, M. C. P. (2011). Vivenciando o cuidado no contexto de uma casa de parto: o olhar das usuárias. Revista da Escola de Enfermagem da USP, 45(1), 62-70. 10.1590/S0080-62342011000100009 
Heidegger, M. (2014). Ser e tempo. 9. ed. Rio de Janeiro, RJ: Vozes.

Jesus, M. C. P., Capalbo, C., Merighi, M. A. B., Oliveira, D. M., Tocantins, F. R., Rodrigues, B. M. R. D., Ciuffo, L. L. (2013). The social phenomenology of Alfred Schütz and its contribution for the nursing. Revista da Escola de Enfermagem da USP, 47(3), 736-41. 10.1590/S0080-623420130000300030

Jorge, R. J. B., Diógenes, M. A. R., Mendonça, F. A. C., Sampaio, L. R. L., \& Jorge Júnior, R. (2011). Exame Papanicolaou: sentimentos relatados por profissionais de enfermagem ao se submeterem a esse exame. Ciência \& Saúde Coletiva, 16(5), 2443-51. 10.1590/S1413-81232011000500013

Labronici, L. M. (2012). Processo de resiliência nas mulheres vítimas de violência doméstica: um olhar fenomenológico. Texto \& Contexto - Enfermagem, 21(3), 625-32. 10.1590/S0104-07072012000300018

Labronici, L. M., Fegadoli, D., \& Correa, M. E. C. (2010). Significado da violência sexual na manifestação da corporeidade: um estudo fenomenológico. Revista da Escola de Enfermagem da USP, 44(2), 401-6. 10.1590/S0080-62342010000200023

Langendorf T. F., Padoin, S. M. M., Paula, C. C., \& Souza, I. E. O. (2015). Compreensão do vivido do ser-casal diante da profilaxia da transmissão vertical do HIV. Revista Gaúcha de Enfermagem. 36(esp), 70-6. 10.1590/1983-1447.2015.esp.56778

Langendorf, T. F., Padoin, S. M. M., Paula, C. C., Souza, I. E. O., \& Aldrighi, J. D. (2016). Profilaxia da transmissão vertical do HIV: cuidado e adesão desvelados por casais. Revista Brasileira de Enfermagem, 69(2), 254-60. 10.1590/0034-7167.2016690210i

Langendorf, T. F., Padoin, S. M. M., Paula, C. C., Souza, I. E. O., \& Bubadué, R. M. (2015). Revealing the relationship of couples facing prophylaxis of vertical transmission of HIV. Investigación y Educación en Enfermería, 33(3), 539-46. 10.17533/udea.iee.v33n3a18

Langendorf, T. F., Padoin, S. M. M., Paula, C. C., Souza, I. E. O., Terra, M. G., \& Silva C. B. (2015). Cotidiano do ser-casal: significados da profilaxia da transmissão vertical do HIV e possibilidades assistenciais. Escola Anna Nery Revista de Enfermagem, 19(2), 259-64. 10.5935/1414-8145.20150034

Leite, P. C., Merighi, M. A. B., \& Silva, A. (2007a). A vivência de uma trabalhadora de enfermagem portadora de lesão "de quervain”. Revista LatinoAmericana de Enfermagem, 15(2), 253-8. 10.1590/S0104-11692007000200010

Leite, P. C., Merighi, M. A. B., \& Silva, A. (2007b). O cotidiano de trabalhadoras de enfermagem acometidas por distúrbios osteomusculares relacionados ao trabalho (DORT) sob a luz da fenomenologia heideggeriana. Online Brazilian Journal of Nursing (Online), 6(3). http://www.objnursing.uff.br/index.php/nursing/article/view/j.1676-4285.2007.1069/259

Lima, S. P., Santos, E. K. A., Erdmann, A. L., \& Souza, A. I. J. (2018). Desvelando o significado da experiência vivida para o ser-mulher na amamentação com complicações puerperais. Texto \& Contexto - Enfermagem, 27(1), e0880016. 10.1590/0104-07072018000880016

Lopez, K. A., \& Willis, D. G. (2004). Descriptive Versus Interpretive Phenomenology: their contributions to Nursing Knowledge. Qualitative Health Research, 14(5), 726-35. 10.1177/1049732304263638

Machado, A. G., Padoin, S. M. M., Paula, C. C., Vieira, L. B., \& Carmo, D. R. P. (2010). Análise compreensiva dos significados de estar gestante e ter HIV/AIDS. Revista da Rede de Enfermagem do Nordeste, 11(2), 79-85. http://periodicos.ufc.br/rene/article/view/4529/3413

Machineski, G. G., Schneider, J. F., \& Bastos, C. C. B. C. (2006). Corporeidade da mulher no pós-parto: uma compreensão da linguagem em Maurice Merleau-Ponty. Revista Gaúcha de Enfermagem, 27(3), 408-16. https://www.scielo.br/scielo.php?script=sci_nlinks\&ref=000102\&pid=S0104$1169201000040001100007 \& \operatorname{lng}=\mathrm{en}$

Madeira, A. M. F., Almeida, G. B. S., \& Jesus, M. C. P. (2007). Refletindo sobre a sexualidade da mulher mastectomizada. Revista Mineira de Enfermagem, 11(3), 254-57. http://www.reme.org.br/artigo/detalhes/343

Medeiros, M. B., Silva, R. M. C. R. A., Pereira, E. R., Melo, S. H. S., Joaquim, F. L., Santos, B. M., \& Goés, T. R. P. (2019). Percepção de mulheres com câncer de mama em quimioterapia: uma análise compreensiva. Revista Brasileira de Enfermagem, 72(Suppl 3), 103-10. 10.1590/0034-7167-2018-0165

Melo, M. C. S. C., \& Souza, I. E. O. (2012). Ambiguidade - modo de ser da mulher na prevenção secundária do câncer de mama. Escola Anna Nery Revista de Enfermagem, 16(1), 41-8. 10.1590/S1414-81452012000100006

Melo, R. O., Moreira, R. C. R., \& Lopes, R. L. M. (2015). Lesões precursoras de câncer cervical: significado para mulheres em um centro de referência no Brasil. Revista de Pesquisa: Cuidado é Fundamental Online, 7(4), 3327-38. 10.9789/2175-5361.2015.v7i4. 3327-3338

Merighi, M. A. B., Carvalho, G. M., \& Suletroni, V. P. (2007). O processo de parto e nascimento: visão das mulheres que possuem convênio saúde na perspectiva da fenomenologia social. Acta Paulista de Enfermagem, 20(4), 434-40. 10.1590/S0103-21002007000400008

Merighi, M. A. B., Gonçalves, R., \& Rodrigues, I. G. (2006). Vivenciando o período puerperal: uma abordagem compreensiva da Fenomenologia Social. Revista Brasileira de Enfermagem, 59(6), 775-9. 10.1590/S0034-71672006000600010

Merighi, M.A.B., Hamano, L., \& Cavalcante, L.G. (2002). O exame preventivo do câncer cérvico-uterino: conhecimento e significado para as funcionárias de uma escola de Enfermagem de uma Instituição Pública. Revista da Escola de Enfermagem da USP, 36, (3), 289-296. 10.1590/S0080-62342002000300012

Merighi, M.A.B., Oliveira, D.M., Jesus, M.C.P., Hoga, L.A.K., \& Pedroso, A.G.O. (2012). Experiências e expectativas de mulheres submetidas a histerectomia. Texto \& Contexto - Enfermagem, 21, (3), 608-615. 10.1590/S0104-07072012000300016

Merighi, M. A. B., Oliveira, D. M., Jesus, M. C. P., Souto, R. Q., \& Thamada, A. A. (2013). Mulheres idosas: desvelando suas vivências e necessidades de cuidado. Revista da Escola de Enfermagem da USP, 47(2), 408-14. 10.1590/S0080-62342013000200019

Merighi, M. A. B., Rodrigues, R. T. F., \& Domingos, S. R. F. (2007). Necessidades de cuidado das mulheres grávidas que possuem convênio saúde: abordagem compreensiva da fenomenologia social. Revista Latino-Americana de Enfermagem, 15(5), 914-21. 10.1590/S0104-11692007000500006 
Merleau-Ponty, M. (2011). 4. ed. Fenomenologia da Percepção. São Paulo, SP: Martins Fontes.

Mesquita, A. A., Dias, M. O., Almeida, I. S., \& Zveiter, M. (2015). Compreendendo o temor do ser no mundo gestante de baixo risco no último trimestre gestacional Cogitare Enfermagem, 20(4), 655-61. 10.5380/ce.v20i4.40492

Monteiro, C. F. S., \& Souza, I. E. O. (2007). Vivência da violência conjugal: fatos do cotidiano. Texto \& Contexto - Enfermagem, 16(1), 26-31. 10.1590/S0104-07072007000100003

Moreira, I. C. C. C., \& Monteiro, C. F. S. (2012). A violência no cotidiano da prostituição: invisibilidades e ambiguidades. Revista Latino-Americana de Enfermagem, 20(5), 954-60. 10.1590/S0104-11692012000500018

Moreira, R. C. R., \& Lopes, R. L. M. (2013). Prevenção do câncer de colo de útero: desvelando a impessoalidade na voz de gestantes. Ciência, Cuidado e Saúde, 12(4), 768-75. 10.4025/cienccuidsaude.v12i4.18973

Moreira, R. C. R., Lopes, R. L. M., \& Diniz, N. M. F. (2013). Prevenção do câncer do colo do útero em gestantes: um estudo fenomenológico. Online Brazilian Journal of Nursing (Online), 12(3). 10.5935/1676-4285.20134011

Moreira, R. C. R., Lopes, R. L. M., Peñarrieta, E. C. S., Gonzaga, R. J., Servo, M. L. S., \& Nascimento, M. A. A. (2017). Abordagem fenomenológica do câncer do colo do útero em gestantes: aspectos da prevenção. Revista Cubana de Enfermería, 33(2). http://www.revenfermeria.sld.cu/index.php/enf/article/view/1159

Oliveira, D. M., Merighi, M. A. B., \& Jesus, M. C. P. (2014). A decisão da mulher obesa pela cirurgia bariátrica à luz da fenomenologia social. Revista da Escola de Enfermagem da USP, 48(6), 970-6. 10.1590/S0080-623420140000700002

Oliveira, D. M., Merighi, M. A. B., Kortchmar, E., Braga, V. A., Silva, M. H., \& Jesus, M. C. P. (2016). Vivência de mulheres no pós-operatório de cirurgia bariátrica: um estudo Fenomenológico. Online Brazilian Journal of Nursing (Online), 15(1), 1-10. 10.17665/1676-4285.20165167

Oliveira, M. I. C., Souza, I. E. O., Santos, E. M., \& Camacho, L. A. B. (2010). Avaliação do apoio recebido para amamentar: significados de mulheres usuárias de unidades básicas de saúde do Estado do Rio de Janeiro. Ciência \& Saúde Coletiva, 15(2), 599-608. 10.1590/S1413-81232010000200036

Oliveira, P. P., Viegas, S. M. F., Santos, W. J., Silveira, E. A. A., \& Elias, S. C. (2015). Mulheres vítimas de violência doméstica: uma abordagem fenomenológica. Texto \& Contexto - Enfermagem, 24(1), 196-203. 10.1590/0104-07072015002900013

Oliveira, V. J., Madeira, A. M. F., \& Penna, C. M. M. (2011). Vivenciando a gravidez de alto risco entre a luz e a escuridão. Revista da Rede de Enfermagem do Nordeste, 12(1), 49-56. http://periodicos.ufc.br/rene/article/view/4119

Padoin, S. M. M., \& Souza, I. E. O. (2008). A compreensão do temor como modo de disposição da mulher com HIV diante da (im)possibilidade de amamentar. Texto \& Contexto - Enfermagem, 17(3), 510-8. 10.1590/S0104-07072008000300012

Padoin, S. M. M., \& Souza, I. E. O. (2006). Ocupação da mulher com HIV/AIDS: o cotidiano diante da (im)possibilidade de amamentar. DST - Jornal brasileiro de doenças sexualmente transmissíveis, 18(4), 241-6. http://www.dst.uff.br/revista18-4-2006/CAP4AOcupacaodaMulhercomHIV.pdf

Padoin, S. M. M., Souza, I. E. O., \& Paula, C. C. (2010). Cotidianidade da mulher que tem HIV/AIDS: modo de ser diante da (im)possibilidade de amamentar. Revista Gaúcha de Enfermagem, 31(1), 77-83. 10.1590/S1983-14472010000100011

Padoin, S. M. M., Terra, M. G., \& Souza. I. E. O. (2011). Mundo da vida da mulher que tem HIV/Aids no cotidiano da (im)possibilidade de amamentar. Escola Anna Nery Revista de Enfermagem, 15(1), 13-21. 10.1590/S1414-81452011000100003

Paiva, A.C.P.C., Elias, E.A., Souza, I.E.O., Moreira, M.C., Melo, M.C.S.C., \& Amorim, T.V. (2020). Cuidado de enfermagem na perspectiva do mundo da vida da mulher-que-vivencia-linfedema-decorrente-do-tratamento-de-câncer-de-mama. Escola Anna Nery Revista de Enfermagem, 24 , (2), e20190176. 10.1590/2177-9465-EAN-2019-0176

Paiva, A.C.P.C., Salimena, A.M;O., Souza, I.E.O., \& Melo, M.C.S.C. (2015). Significado do diagnóstico de neoplasia mamária: compreensão fenomenológica de mulheres. Revista Baiana de Enfermagem, 29, (1), 59-67. 10.18471/rbe.v29i1.12239

Paula, A. F., \& Madeira, A. M. F. (2003). O exame colpocitológico sob a ótica da mulher que o vivencia. Revista da Escola de Enfermagem da USP, 37(3), 88-96. https://www.scielo.br/pdf/reeusp/v37n3/11.pdf

Peters, M. D. J., Godfrey, C., McInerney, P., Munn, Z., Tricco, A. C., \& Khalil, H. (2020). Chapter 11: Scoping Reviews (2020 version). In: Aromataris E, Munn Z (Editors). JBI Manual for Evidence Synthesis, JBI, 2020. 10.46658/JBIMES-20-12

Piolli, K. C., Decesaro, M. N., \& Sales, C. A. (2018). O (des)cuidar-se como mulher ao ser cuidadora do companheiro com câncer. Revista Gaúcha de Enfermagem, 39, e2016-0073. 10.1590/1983-1447.2018.2016-0069

Reis, S. E. H., Bonadio, I. C., Tsunechiro, M. A., \& Merighi, M. A. B. (2008). O cotidiano de mulheres grávidas moradoras no alojamento de uma maternidade social. Texto \& Contexto - Enfermagem, 17(3), 492-501. 10.1590/S0104-07072008000300010

Ribeiro, M. O. S., Salimena, A. M. O., Vargens, O. M. C., Souza, R. C. M., Paiva, A. C. P. C., \& Amorim, T. V. (2019). Vivências de mulheres enfrentando a histerectomia: estudo fenomenológico. Nursing (Säo Paulo), 22(253), 3011-5 . 10.36489/nursing.2019v22i253p3011-3015

Roma, J.C. (2019). Os objetivos de desenvolvimento do milênio e sua transição para os objetivos de desenvolvimento sustentável. Ciência e Cultura, 71(1), 33-39. 10.21800/2317-66602019000100011

Rosa, M. T. S., \& Sales, C. A. (2008). Vivências de mulheres submetidas à braquiterapia: compreensão existencial. Revista Eletrônica de Enfermagem, 10(4), 990-1003. 10.5216/ree.v10.46776 
Salci, M. A., Sales, C. A., \& Marcon, S. S. (2009). Sentimentos de mulheres ao receber o diagnóstico de câncer. Revista Enfermagem UERJ, 17(1), 46-51. http://files.bvs.br/upload/S/0104-3552/2009/v17n1/a008.pdf

Sales, C. A., \& Molina, M. A. S. (2004). O significado do câncer no cotidiano de mulheres em tratamento quimioterápico. Revista Brasileira de Enfermagem, 57(6), 720-3. 10.1590/S0034-71672004000600018

Salimena, A. M. O., \& Souza, I. E. O. (2008). O sentido da sexualidade de mulheres submetidas a histerectomia: uma contribuição da enfermagem para a integralidade da assistência ginecológica. Escola Anna Nery Revista de Enfermagem, 12(4), 637-44. 10.1590/S1414-81452008000400005

Salimena, A. M. O., \& Souza, I. E. O. (2010). Cotidiano da mulher pós-histerectomia à luz do pensamento de Heidegger. Revista Brasileira de Enfermagem 2010, 63(2), 196-202. 10.1590/S0034-71672010000200005

Salimena, A. M. O., Souza, I. E. O, Cadete, M. M. M. (2009). O movimento existencial da mulher pós-histerectomia: temor, possibilidade e decisão contribuições para a enfermagem ginecológica. Revista Mineira de Enfermagem, 13(3), 343-8. https://cdn.publisher.gn1.link/reme.org.br/pdf/v13n3a05.pdf

Santos, B. (2008). Um discurso sobre as ciências. 5d. São Paulo, SP: Cortez.

Santos, G. C., \& Gonçalves, L. L. C. (2006). Mulheres mastectomizadas com recidiva de câncer: o significado do novo ciclo de quimioterapia. Revista Enfermagem UERJ, 14(2), 239-44.

Scheler, M. (2012). Da reviravolta dos valores. 2. ed. Petrópolis, RJ: Vozes, 2012.

Schütz A. (1972). Fenomenologia del mundo social: introducción a la sociología comprensiva. Buenos Aires, AR: Paidós.

Silva, A. L., Silva, L. F., Souza, I. E. O., Guedes, M. V. C., Araújo, M. A. M., \& Farias, M. S. (2017). Ser mulher com cardiopatia e desenvolver lesão por pressão na internação hospitalar: sentido do temor. Revista Enfermagem UERJ, 25, e14509. 10.12957/reuerj.2017.14509

Silva, A. R. B., \& Merighi, M. A. B. (2006). Compreendendo o estar com câncer ginecológico avançado câncer ginecológico avançado: uma abordagem heideggeriana Revista da Escola de Enfermagem da USP, 40(2), 253-60. 10.1590/S0080-62342006000200014

Silva, G. P. S., Jesus, M. C. P., Merighi, M. A. B., Domingos, S. R. F., \& Oliveira, D. M. (2014). Experiência de mulheres com a cesariana sob a ótica da fenomenologia social. Online Brazilian Journal of Nursing (Online), 13(1), 5-14. 10.17665/1676-4285.2014v13n1

Silva, L. A., Alves, V. H., Rodrigues, D. P., Padoin, S. M. M., Branco, M. B. L. R., \& Souza, R. M. P. (2015). A qualidade de uma rede integrada: acessibilidade e cobertura no pré-natal. Revista de Pesquisa: Cuidado é Fundamental Online, 7(2), 2298-309. 10.9789/2175-5361.2015.v7i2.2298-2309

Silva, L. A., Alves, V. H., Rodrigues, D. P., Vieira, B. D. G., Marchiori, G. R. S., \& Santos, M. V. (2018). A humanização do cuidado pré-natal na perspectiva valorativa das mulheres gestantes. Revista de Pesquisa: Cuidado é Fundamental Online, 10(4), 1014-9. 10.9789/2175-5361.2018.v10i4.1014-1019

Silva, M. G., \& Boemer, M. R. (2009). Vivendo o envelhecer: uma perspectiva fenomenológica. Revista Latino-Americana de Enfermagem, 17(3), 380-6. 10.1590/S0104-11692009000300016

Silva, M. R. B., \& Lopes, R. L. M. A. (2004). Leishmaniose Tegumentar Americana na perspectiva de quem a vivencia. Online Brazilian Journal of Nursing (Online), 3(2), 16-24. http://www.objnursing.uff.br/index.php/nursing/article/view/4906/html_776

Simões, S. M. F., \& Souza, I. E. O. (1997). Vivência de parturientes: observação de enfermagem. Revista Brasileira de Enfermagem, 50(4), 507-16. 10.1590/S0034-71671997000400006

Simões, S. M. F., \& Souza, I. E. O. (1999). A mulher e a decisão no cuidar da própria saúde: um estudo compreensivo sob a ótica da enfermagem. Revista Enfermagem UERJ, 7(2), 123-8.

Soares, G. R. S., Cortez, E. A., Silva, R. M. A., Sá, S. P. C., \& Simões, S. M. F. (2015). O cuidar em saúde mental: contribuições fenomenológicas acerca de mulheres trabalhadoras em situação de climatério. Revista Cubana de Enfermería, 31(2). http://www.revenfermeria.sld.cu/index.php/enf/article/view/673

Soccol, K. L. S., Terra, M. G., Padoin, S. M. M., Ribeiro, D. B., Siqueira, D. F., \& Canabarro, J. L. (2018). Motivos do abuso de substâncias psicoativas por mulheres assistidas em Centro de Atenção Psicossocial. Revista Gaúcha de Enfermagem, 39, e20170281. 10.1590/1983-1447.2018.20170281

Sodré, T. M., Bonadio, I. C., Jesus, M. C. P., \& Merighi, M. A. B. (2010). Necessidade de cuidado e desejo de participação no parto de gestantes residentes em Londrina-Paraná. Texto \& Contexto - Enfermagem, 19(3), 452-60. 10.1590/S0104-07072010000300006

Souto, M. D., \& Souza, I. E. O. (2004). Sexualidade da mulher após a mastectomia. Escola Anna Nery Revista de Enfermagem, 8(3), 402-10. https://www.redalyc.org/pdf/1277/127718062011.pdf

Souto, R. Q., Merighi, M. A. B., Guruge, S., \& Jesus, M. C. P. (2015). Older Brazilian women's experience of psychological domestic violence: a social phenomenological study. International Journal for Equity in Health, 14(44). 10.1186/s12939-015-0173-Z

Souza, I. E. O. (1997). O desvelar do ser-gestante diante da possibilidade de amamentação. Escola Anna Nery Revista de Enfermagem, 1, (esp), $135-142$.

Souza, M. H. N., Souza, I. E. O., \& Tocantins, F. R. (2009). Abordagem da fenomenologia sociológica na investigação da mulher que amamenta. Revista Enfermagem UERJ, 17(1), 52-56. http://files.bvs.br/upload/S/0104-3552/2009/v17n1/a009.pdf

Toneti, B. F., Avelar, J. M. P., Sousa, F. H., Toneti, A. N., Sonobe, H. M., \& Sawada, N. O. (2019). O significado de uma terapia integrativa de relaxamento guiado para mulheres com câncer de mama. Revista da Escola de Enfermagem da USP, 53, e03497. 10.1590/S1980-220X2018024103497

Tricco, A. C., Lillie, E., Zarin, W., O'Brien, K. K., Colquhoun, H., Levac, D., Strauss, S. E. (2018). PRISMA Extension for Scoping Reviews (PRISMAScR): Checklist and Explanation. Annals of Internal Medicine, 169(7), 467-73. 10.7326/M18-0850 
Research, Society and Development, v. 10, n. 16, e528101623928, 2021

(CC BY 4.0) | ISSN 2525-3409 | DOI: http://dx.doi.org/10.33448/rsd-v10i16.23928

Trigueiro, T. H., Silva, M. H., Merighi, M. A. B., Oliveira, D. M., \& Jesus, M. C. P. (2017). O sofrimento psíquico no cotidiano de mulheres que vivenciaram a violência sexual: estudo fenomenológico. Escola Anna Nery Revista de Enfermagem, 21(3), e20160282. 10.1590/2177-9465-ean-2016-0282

Trigueiro, T. H., Silva, M. H., Oliveira, D. M., Jesus, M. C. P., \& Merighi, M. A. B. (2018). Não adesão ao seguimento ambulatorial por mulheres que experienciaram a violência sexual. Texto \& Contexto - Enfermagem, 27(1), e6490015. 10.1590/0104-07072018006490015

United Nations General Assembly. (2015). Transforming our world: the 2030 Agenda for Sustainable Development. https://sustainabledevelopment.un.org/content/documents/21252030\%20Agenda\%20for\%20Sustainable\%20Development\%20web.pdf

Vieira, L. B., Padoin, S. M. M., Souza, I. E. O., \& Paula, C. C. (2011a). Perspectivas para o cuidado de enfermagem às mulheres que denunciam a violência vivida. Escola Anna Nery Revista de Enfermagem, 15(4), 678-85. 10.1590/S1414-81452011000400004

Vieira, L. B., Padoin, S. M. M., Souza, I. E. O., \& Paula, C. C. (2012). Intencionalidades de mulheres que decidem denunciar situações de violência. Acta Paulista de Enfermagem, 25(3), 423-9. 10.1590/S0103-21002012000300016

Vieira, L. B., Padoin, S. M. M., Souza, I. E. O., Paula, C. C., \& Terra, M. G. (2011b). Típico da ação das mulheres que denunciam o vivido da violência: $\begin{array}{llllll}\text { contribuições para } & \text { a } & \text { Enfermagem. } & \text { Enfermagem } & \text { UERJ, } & \text { 19(3), }\end{array}$ https://pdfs.semanticscholar.org/5a34/81a4ceeab7a61257c6f3402844f4f357149d.pdf

Vieira, L. B., Padoin, S. M. M., Souza, I. E. O., Paula, C. C., \& Terra, M. G. (2013). Necessidades assistenciais de mulheres que denunciam na delegacia de polícia a vivência da violência Aquichan, 13(2), 197-205. http://www.scielo.org.co/pdf/aqui/v13n2/v13n2a06.pdf 